\title{
Attitude towards diabetes and social and family support among type 2 diabetes patients attending a tertiary-care hospital in Bangladesh: a cross-sectional study
}

Md. Shajedur Rahman Shawon ${ }^{1 *}$, Fariha Binte Hossain ${ }^{1 \dagger}$, Gourab Adhikary ${ }^{1}$, Rajat Das Gupta ${ }^{2}$, Mohammad Rashidul Hashan ${ }^{2}$, Md. Fazla Rabbi ${ }^{2}$ and G. U. Ahsan ${ }^{1}$

\begin{abstract}
Background: Bangladesh has been suffering from an epidemiological transition from infectious and maternal diseases to non-communicable lifestyle-related diseases like diabetes, cardiovascular diseases, cancers etc. The burden of diabetes has been increasing rapidly due to high incidence as well as poor glycemic control leading to various macro and micro-vascular complications. In this study, we aim to assess the attitude towards diabetes and social and family support among the Bangladeshi type 2 diabetic mellitus (T2DM) patients.

Methods: This was a cross-sectional study among 144 patients with T2DM at the medicine outpatient department of Dhaka Medical College Hospital (DMCH) in Dhaka, Bangladesh between 1 July and 31 July 2014. Data collection was done by interviewing patients using structured questionnaire. Understanding diabetes, education/advice received, attitude towards diabetes, family and friend support were measured by validated scales adapted from diabetes care profile.

Results: This study includes a total of 144 patients (101 males and 43 females) with type 2 diabetes aged between 20 and 84 years. $87 \%$ of the patients had inadequate blood glucose control (fasting blood sugar $>7.2 \mathrm{mmol} / \mathrm{L}$ or $>130 \mathrm{mg} / \mathrm{dl}$ ). Statistically significant differences were observed in the mean scores of various attitude scales (i.e. positive, negative, care ability and self-care adherence scale) among patients with adequate and inadequate blood glucose control $(p<0.05)$. Statistically significant positive correlations were found between these three categories of social and family support. Self-satisfaction with diabetic care was significantly associated with adequate blood glucose control $(p=0.05)$.

Conclusions: Positive attitude towards diabetes management and support from friends and family were associated with adequate diabetes management. Appropriate public health interventions should be designed to educate and motivate the family members to offer greater support to the diabetes patients.
\end{abstract}

Keywords: Type 2 diabetes mellitus, Glycemic status, Bangladesh, Social and family support, Attitude, Fasting blood sugar

\section{Background}

Type 2 diabetes mellitus (T2DM) is a growing clinical and public health problem globally. International Diabetes

\footnotetext{
*Correspondence: dr.shajedur@gmail.com

${ }^{\dagger}$ Md. Shajedur Rahman Shawon and Fariha Binte Hossain contributed equally to this work

1 Department of Public Health, North South University, Bashundhara, Dhaka 1229, Bangladesh

Full list of author information is available at the end of the article
}

Federation (IDF) has reported that T2DM is affecting approximately 171 million people worldwide and $80 \%$ of all people affected by diabetes are from the low and middle income countries (LMICs) [1-3]. South East Asia would most likely to experience the highest toll from this epidemic as diabetes prevalence is expected to rise by $71 \%$ within next 25 years and countries in this region are least equipped to tackle this emerging crisis [2-4]. 
There has been an emerging epidemic of non-communicable lifestyle diseases like diabetes, cardiovascular diseases, cancer etc. in Bangladesh. This epidemiological transition from infectious and maternal diseases to chronic diseases is mainly due to demographic transition, increased prevalence of obesity and adoption of westernized lifestyles [5]. According to IDF report (2011), the number of diabetes patients in Bangladesh is approximately 8.4 million which is going to be doubled by the year 2030 [6]. According to a recent meta-analysis, the pooled prevalence of type 2 diabetes mellitus was $6.7 \%(4.9-8.6 \%)$ [7]. Higher prevalence of diabetes was observed in urban $(8.1 \%)$ compared to rural $(2.3 \%)$ population [4]. Another study found the prevalence of T2DM was $5 \%$ in middle-income neighborhood in the capital city, Dhaka [8].

T2DM patients suffer from various micro and macrovascular complications due to inadequate glycemic control. These complications add up to the public health burden of T2DM [9]. Good glycemic control leads not only to higher quality of life [10], but also reduces longterm complications $[11,12]$. However, previous studies showed high proportions of diabetes patients had inadequate glycemic control [13, 14].

Although better management of T2DM depends on many factors [15-19], patient's attitude towards diabetes along with social and family support contribute to better management of diabetes [20]. Diabetes patients can obtain support towards their disease from family members, friends, healthcare providers and patient networks which can lead to better control of diabetes [21-24]. Conversely, lack of social and family support reduce the motivation and effort towards self-care management of diabetes [25].

In this study, we aim to assess the attitude towards diabetes and social and family support among the Bangladeshi type 2 diabetic patients. The result of this study will guide the clinicians and public health policy makers to develop and implement diabetes control programs in Bangladesh and other developing countries.

\section{Methods}

\section{Study design and population}

A cross-sectional study was carried out among 144 patients with type 2 diabetes at the medicine outpatient department of Dhaka Medical College Hospital (DMCH) in Dhaka, Bangladesh between 1 July and 31 July 2014. $\mathrm{DMCH}$ is the largest public hospital providing affordable healthcare to a large number of patients from all socioeconomic strata through its outpatient, inpatient and emergency facilities [26].

All consecutive adult patients aged 18 years or more who had been previously diagnosed with type 2 diabetes by a qualified healthcare professional e.g. physician, nurse, SACMO (Sub-assistant Community Medical Officer) were included in the study. The exclusion criteria for this study were-(i) Patients with type 1 diabetes mellitus; (ii) patients with gestational diabetes; (iii) Newly diagnosed with type 2 diabetes on the day of survey; (iv) Patients with any diabetes-related-complications requiring hospital admission.

\section{Data collection tool}

Data collection was done by face-to-face interview using a structured questionnaire. Information on socio-demographic status, diabetes care, understanding diabetes, education/advice received, family and friend support and self-perception about glycemic control was collected. All available last readings of glycated hemoglobin (HbA1c) and fasting blood sugar measurements were abstracted from patients' medical records.

Understanding diabetes, education/advice received, attitude towards diabetes, family and friend support were measured by validated scales adapted from diabetes care profile (DCP) [27]. DCP was developed by Michigan Diabetes Research and Training Center to measure the social and psychological factors associated with diabetes [28].

Attitude towards diabetes scale consisted of 17 items and measured positive attitude, negative attitude, care ability, importance of care, and self-care adherence. Each item was rated on a five-point Likert scale $(1=$ strongly disagree, 2 = disagree, $3=$ neutral, $4=$ agree, and $5=$ strongly agree). Family and friend support for diabetes questions were divided into 3 categories-support needed, support received and support attitude. In each category there were six items with five-point likert scale $(1=$ strongly disagree, $2=$ disagree, $3=$ neutral, $4=$ agree, and $5=$ strongly agree). Reverse scoring was done for negatively worded questions. Mean scores were calculated for each category by summing the scores of respective items and then divided by count of non-missing items.

Self-perception of glycemic control was assessed by using a scale with five levels: very good, good, fair, poor and very poor. A single global question "If you were to spend the rest of your life with your diabetes treatment the way it is today, how you would feel about this? (very satisfied, somewhat satisfied, neither dissatisfied nor satisfied, somewhat dissatisfied, or very dissatisfied") was asked to measure satisfaction with current diabetes treatment [29].

A draft questionnaire was developed and piloted on a sample of volunteer patients to refine the wording of the items and ensure clarity of text. The questionnaire was translated into Bengali and then, again translated back to English to maintain the consistency in the translation 
process. Three qualified research physicians were involved in data collection.

\section{Operational definitions}

Patients were considered to have type 2 diabetes if they were diagnosed by a qualified healthcare professional e.g. physician, nurse, SACMO etc. Patients who responded "Strongly agree" or "Agree" to the question "Do you follow the diet plan advised by your physician/dietitian?" were categorized as adherent to diet. Patients were considered as adherent to treatment plan if they responded "Strongly agree" or "Agree" to the question "Do you follow the treatment plan advised by your physician?" Physically active was considered if patients were engaged in doing exercise at least for $30 \mathrm{~min}$ for three or more days in a week. Diabetes treatment modality was categorized into oral anti-hyperglycemic agent (OAA), alone, insulin alone and oral anti-hyperglycemic agents (OAA) and insulin together. Regular checkup for diabetes was considered if the patients said they visited doctor for diabetes treatment at least once in 2 months or more frequently. We defined inadequate blood glucose control if fasting blood glucose $\geq 7.2 \mathrm{mmol} / \mathrm{L}$ (or $130 \mathrm{mg} / \mathrm{dl}$ ). Patients were categorized as satisfied with current diabetic treatment if they answered either "very satisfied" or "somewhat satisfied" to the question "If you were to spend the rest of your life with your diabetes treatment the way it is today, how you would feel about this?"

\section{Statistical analysis}

Data were presented as frequency and proportions for categorical variables and mean \pm standard deviation (SD) for continuous variables. Appropriate statistical tests i.e. Chi square tests, independent sample $t$ tests were performed. Correlation matrix was developed to find out the association between support needed, support received and support attitude. All statistical tests were considered significant at $p$ value $<0.05$. Statistical analyses were performed using SPSS version 22.0 for Windows (IBM, NY, USA).

\section{Results}

\section{Participants' characteristics}

This study included a total of 144 patients (101 males and 43 females) with type 2 diabetes aged between 20 and 84 years. Majority of the participants were married $(78.5 \%)$ and followed Islam $(86.1 \%)$ as religion. $29.2 \%$ of the participants were working fulltime ( $35 \mathrm{~h}$ or more in a week); $23.6 \%$ were homemakers; about $27 \%$ were either retired or unemployed and not looking for work. Among the participants $54 \%$ were non-smoker, $27 \%$ were current smoker and $19 \%$ were ever smoker. More than half $(61.8 \%)$ of the participants had concurrent history of hypertension and about one-third had history of dyslipidemia. The socio-demographic and clinical characteristics of the participants is given below [see Table 1].

\section{Information about diabetes}

The mean age of diagnosis with type 2 diabetes was $45.62 \pm 10$ years and mean duration of suffering was $8.9 \pm 7.1$ years. Half of the respondents had family history of diabetes. Majority of the patients (42\%) used only OAA, $30 \%$ used only insulin and $28.5 \%$ used both OAA and insulin as their treatment modalities. $50 \%$ patients were having regular checkup (once in 2 months or more frequently) by physician for diabetes. Majority of the patients reported that they followed the advised treatment plan (79.9\%), diet plan (79.9\%) and were physically active $(50.3 \%)$ [see Table 2].

Most of the patients (80\%) reported that they regularly measured their blood sugar level and we found fasting blood sugar information for the last month among $92 \%$ patients in their record books. On the other hand, only $55.6 \%$ patients had $\mathrm{HbA} 1 \mathrm{C}$ information for the last 3 months. Due to lack of HbA1C information in many participants, we calculated adequate blood glucose control $(>7.2 \mathrm{mmol} / \mathrm{L}$ or $>130 \mathrm{mg} / \mathrm{dl})$ and found only $13 \%$ patients had adequate control.

\section{Attitudes towards diabetes}

Attitude towards diabetes was analyzed into five different dimensions i.e. positive attitude, negative attitude, care ability, importance of care and self-care adherence. Statistically significant differences were observed in the mean score of positive attitude scale, negative attitude scale, care ability scale and self-care adherence scale among patients with adequate and inadequate blood glucose control (see Fig. 1).

\section{Social and family support}

Patients with adequate blood glucose control had higher mean scores than patients with inadequate blood glucose control on support needed scale (4.2 vs. $3.8 ; \mathrm{p}=0.160)$, support received scale (3.7 vs. 3.2; $\mathrm{p}=0.056)$ and support attitude ( 4.1 vs. $3.7 ; \mathrm{p}=0.067$ ). Statistically significant positive correlations were found between these three categories of social and family support (see Table 3 ). Spouse (29\%) and family members $(28 \%)$ are found to be the care-giver for most of the diabetic patients. Approximately $14 \%$ of the patients said that they had no caregiver for their diabetes (see Fig. 2).

\section{Self-perception and satisfaction about diabetes}

Most of the patients had good perception about their glycemic control and only $29 \%$ patients perceived their glycemic control as "poor" or "very poor". $42 \%$ patients 
Table 1 Socio-demographic and clinical characteristics of the participants $(n=144)$

\begin{tabular}{|c|c|c|}
\hline Variables & Categories & Number (\%) \\
\hline \multirow[t]{2}{*}{ Gender } & Male & 101 (70.1\%) \\
\hline & Female & $43(29.9 \%)$ \\
\hline Age in years & Mean $\pm S D$ & $54.4 \pm 11.7$ \\
\hline \multirow[t]{4}{*}{ Marital status } & Married & $113(78.5 \%)$ \\
\hline & Widowed & $21(14.6 \%)$ \\
\hline & Separated/divorced & $05(3.5 \%)$ \\
\hline & Never married & 05 (3.5 \%) \\
\hline \multirow[t]{3}{*}{ Religion } & Islam & $124(86.1 \%)$ \\
\hline & Hindu & $19(13.2 \%)$ \\
\hline & Others & $01(0.7 \%)$ \\
\hline \multirow[t]{7}{*}{ Employment status } & Working full time & $42(29.2 \%)$ \\
\hline & Working part-time & $17(11.8 \%)$ \\
\hline & $\begin{array}{l}\text { Unemployed or laid off and } \\
\text { looking for work }\end{array}$ & $07(4.9 \%)$ \\
\hline & $\begin{array}{l}\text { Unemployed and not look- } \\
\text { ing for work }\end{array}$ & $18(12.5 \%)$ \\
\hline & Homemaker & $34(23.6 \%)$ \\
\hline & Retired & $21(14.6 \%)$ \\
\hline & Others & $05(3.5 \%)$ \\
\hline \multirow[t]{3}{*}{ Smoking status } & Non-smoker & $78(54.2 \%)$ \\
\hline & Current smoker & $39(27.1 \%)$ \\
\hline & Ever smoker & $27(18.8 \%)$ \\
\hline \multirow{3}{*}{$\begin{array}{l}\text { Concurrent history of } \\
\text { hypertension }\end{array}$} & Yes & $89(61.8 \%)$ \\
\hline & No & $30(20.8 \%)$ \\
\hline & Don't know & $25(17.4 \%)$ \\
\hline \multirow{3}{*}{$\begin{array}{l}\text { Concurrent history of } \\
\text { dyslipidemia }\end{array}$} & Yes & $48(33.3 \%)$ \\
\hline & No & $35(24.3 \%)$ \\
\hline & Don't know & 61 (42.4\%) \\
\hline
\end{tabular}

were either "very satisfied" or "somewhat satisfied" if they were to spend the rest of their lives with current diabetes treatment. Self-satisfaction with diabetic care was significantly associated with adequate blood glucose control $(\mathrm{p}=0.05)$.

\section{Discussion}

The noteworthy findings of this study are: (i) Type 2 diabetes patients, in general, lack information about HbA1C and other related clinical parameters; (ii) The proportion of T2DM patients with inadequate blood glucose control is $87 \%$ according to fasting blood sugar cutoff $\geq 7.2 \mathrm{mmol} / \mathrm{L}$ or $130 \mathrm{mg} / \mathrm{dl}$; (iii) Significant differences have been observed in the mean scores of attitude between patients with adequate and inadequate blood glucose control; (iv) Significant positive correlation was observed between support attitude of friends and family and support received; (v) Most of the diabetes patients had good perception as well as satisfaction about their
Table 2 Information related to diabetes and diabetic care among the participants

\begin{tabular}{|c|c|c|}
\hline Variables & Categories & Number (\%) \\
\hline Age of diabetes diagnosis, in years & Mean \pm SD & $45.62 \pm 10$ \\
\hline Duration of diabetes, in years & Mean \pm SD & $8.9 \pm 7.1$ \\
\hline \multirow[t]{3}{*}{ Family history of diabetes } & Yes & $73(50.7 \%)$ \\
\hline & No & $35(24.3 \%)$ \\
\hline & Don't know & $36(25 \%)$ \\
\hline \multirow[t]{3}{*}{ Treatment modalities } & OAA only & $60(41.7 \%)$ \\
\hline & Insulin only & $43(29.9 \%)$ \\
\hline & OAA and insulin & $41(28.5 \%)$ \\
\hline \multirow[t]{2}{*}{ Regular checkup for diabetes } & Yes & $72(50 \%)$ \\
\hline & No & $72(50 \%)$ \\
\hline \multirow{2}{*}{$\begin{array}{l}\text { Following treatment plan advised } \\
\text { by the physician }\end{array}$} & Yes & $115(79.9 \%)$ \\
\hline & No & $29(20.1 \%)$ \\
\hline \multirow{2}{*}{$\begin{array}{l}\text { Following diet plan advised by } \\
\text { physician/dietitian }\end{array}$} & Yes & $101(70.1 \%)$ \\
\hline & No & $43(29.9 \%)$ \\
\hline \multirow[t]{2}{*}{ Physically active } & Yes & $72(50.3 \%)$ \\
\hline & No & $71(49.7 \%)$ \\
\hline \multirow{2}{*}{$\begin{array}{l}\text { Suffered from any diabetes related } \\
\text { complications }\end{array}$} & Yes & $89(61.8 \%)$ \\
\hline & No & $55(38.2 \%)$ \\
\hline \multirow[t]{2}{*}{ Testing blood sugar level regularly } & Yes & $114(79.2 \%)$ \\
\hline & No & $30(20.8 \%)$ \\
\hline \multirow{3}{*}{$\begin{array}{l}\text { Keeping record of blood sugar test } \\
\text { results }\end{array}$} & Yes & $44(30.6 \%)$ \\
\hline & No & $56(38.9 \%)$ \\
\hline & Only unusual values & $44(30.6 \%)$ \\
\hline \multirow[t]{2}{*}{ Availability of $\mathrm{HbA} 1 \mathrm{C}$ information } & Yes & $80(55.6 \%)$ \\
\hline & No & $64(44.4 \%)$ \\
\hline \multirow{2}{*}{$\begin{array}{l}\text { Availability of fasting blood sugar } \\
\text { information }\end{array}$} & Yes & $132(91.7 \%)$ \\
\hline & No & $12(8.3 \%)$ \\
\hline
\end{tabular}

$O A A$ oral anti-hyperglycemic agents; $H b A 1 c$ glycated hemoglobin

diabetes management despite the fact that most of them failed to achieve the recommended level of fasting blood glucose for T2DM patients.

The proportion of T2DM patients with poor management of their diabetes was high (87 \%) among the participants, and it was much higher than the findings from studies conducted in many countries. For instance, studies with large sample sizes conducted in the UK [30], Canada [31], Brazil [32] and Venezuela [29] found that the prevalence of inadequate diabetes control were $76,73,73$ and $75 \%$, respectively. However, some studies found much lower prevalence of poor diabetes control [33, 34]. Furthermore, in the US, estimates from the National Health and Nutrition Examination Survey (NHANES) showed a decreasing trend in the prevalence of poor diabetes management (i.e. from 63 to $43 \%$ over the period from 1999 to 2004) [35]. In spite of the fact that these variations in prevalence of 


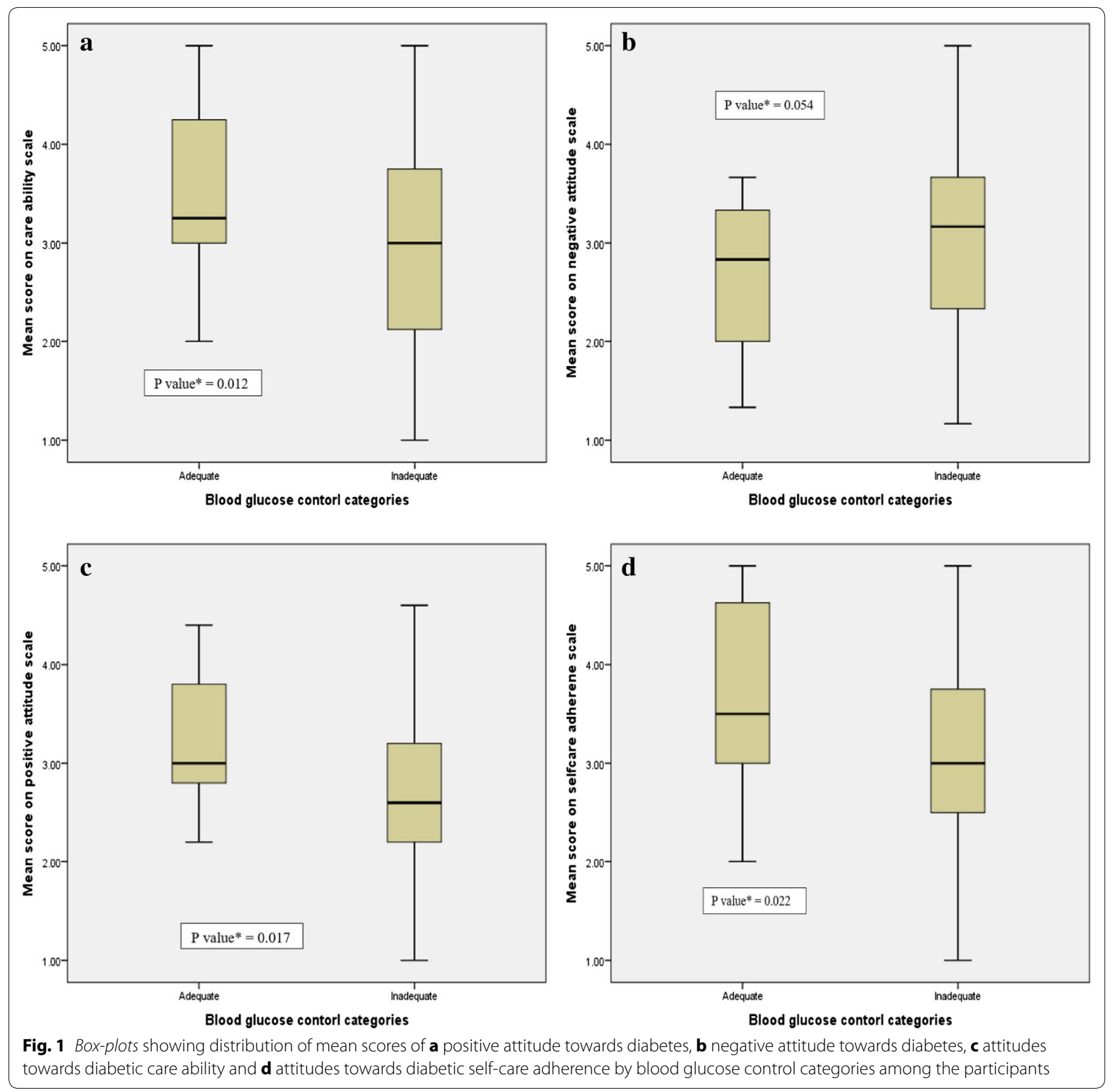

Table 3 Correlation matrix for support needed, support received and support attitude among the participants

\begin{tabular}{llll}
\hline & $\begin{array}{c}\text { Support needed Support } \\
\text { received }\end{array}$ & $\begin{array}{l}\text { Support atti- } \\
\text { tude }\end{array}$ \\
\hline Support needed & 1 & $0.269^{\mathrm{a}}$ & $0.193^{\mathrm{b}}$ \\
Support received & $0.269^{\mathrm{a}}$ & 1 & $0.675^{\mathrm{a}}$ \\
Support attitude & $0.193^{\mathrm{b}}$ & $0.675^{\mathrm{a}}$ & 1 \\
\hline
\end{tabular}

a Pearson correlation is significant at the 0.01 level (2-tailed)

b Pearson correlation is significant at the 0.05 level (2-tailed)

poor glycemic control across different settings might be true, methodological differences (i.e. selection of study populations, methods/definition of outcome ascertainment) might lead to the differences in prevalence estimates [29].

We found that poor blood glucose control was more common among patients who did not follow the advised diet plan. Therefore, patients should be encouraged to follow the diet plan as prescribed by the physician or dietitian. Despite the importance of physical activity and 


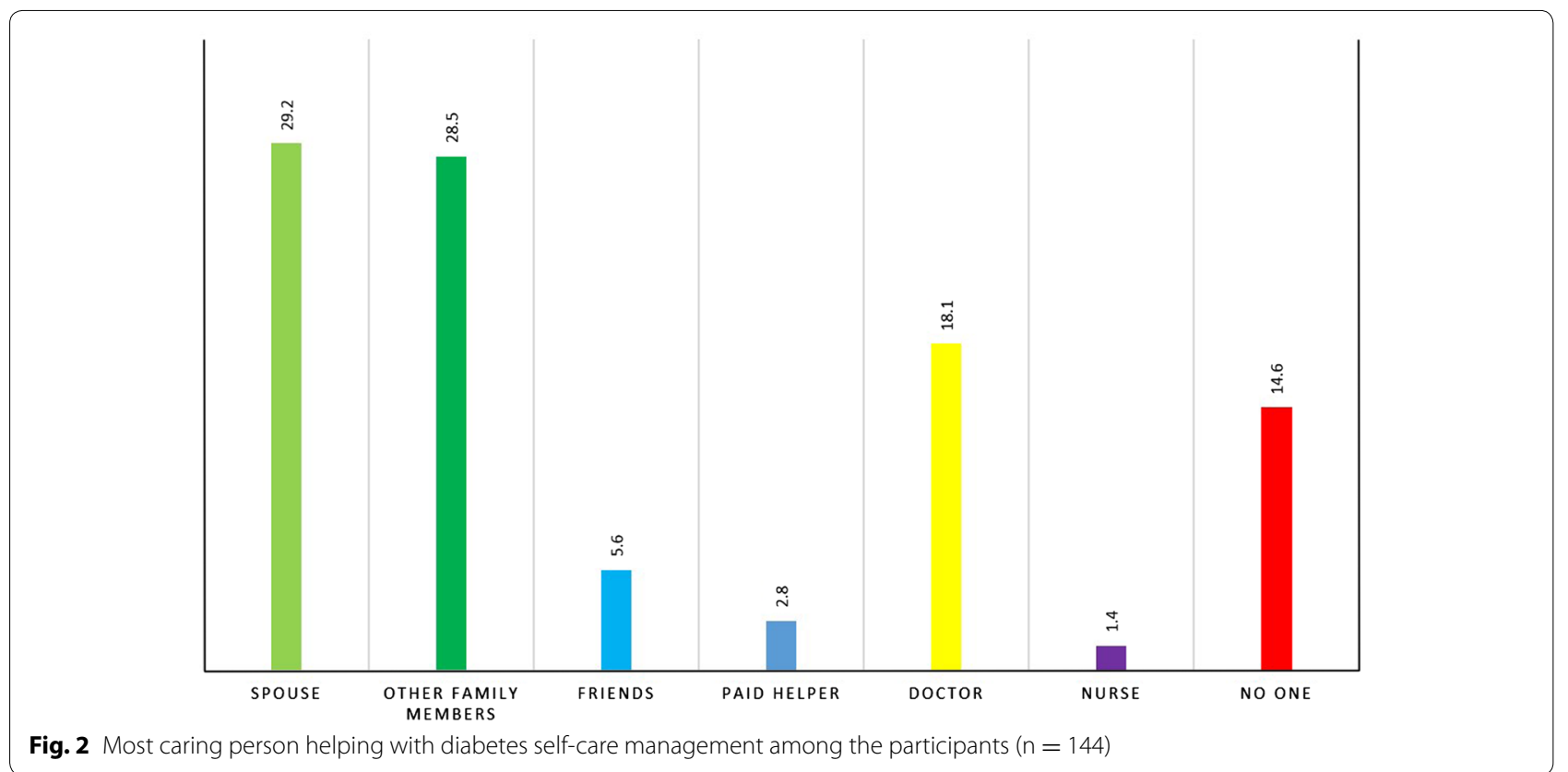

regular checkup by healthcare professionals in controlling diabetes status, a major portion of the participants was found physically inactive as well as not followed on regular basis (see Table 4). Therefore, public health interventions focusing on educating and motivating T2DM patients on regular physical activity and follow-up are crucial.

Table 4 Variables associated with adequate blood glucose control among the type 2 diabetes patients

\begin{tabular}{|c|c|c|c|c|}
\hline Variables & Categories & $\begin{array}{l}\text { Adequate blood glucose } \\
\text { control } \mathbf{n}(\%)\end{array}$ & $\begin{array}{l}\text { Inadequate blood glucose } \\
\text { control } \mathrm{n}(\%)\end{array}$ & $P$ value \\
\hline Age, in years & Mean \pm SD & $49.7 \pm 8.8$ & $54.4 \pm 12.1$ & $0.133^{* *}$ \\
\hline \multirow[t]{2}{*}{ Sex } & Male & $12(13.2 \%)$ & 79 (86.8 \%) & $0.875^{*}$ \\
\hline & Female & $5(12.2 \%)$ & $36(87.8 \%)$ & \\
\hline \multirow[t]{2}{*}{ Duration of suffering from diabetes } & $<5$ years & $6(13.3 \%)$ & $39(86.7 \%)$ & $0.911^{*}$ \\
\hline & $\geq 5$ years & $11(12.6 \%)$ & $76(87.4 \%)$ & \\
\hline \multirow{2}{*}{$\begin{array}{l}\text { Suffered from diabetes related } \\
\text { complications }\end{array}$} & Yes & $6(7.3 \%)$ & 76 (92.7 \%) & $0.015^{*}$ \\
\hline & No & $11(22.0 \%)$ & $39(78.0 \%)$ & \\
\hline \multirow[t]{2}{*}{ Testing blood sugar regularly } & Yes & $14(13.2 \%)$ & $92(86.8 \%)$ & $0.820^{*}$ \\
\hline & No & $3(11.5 \%)$ & $23(88.5 \%)$ & \\
\hline \multirow[t]{2}{*}{ Regular checkup for diabetes } & Yes & $12(17.6 \%)$ & $56(82.4 \%)$ & $0.092^{*}$ \\
\hline & No & $5(7.8 \%)$ & $59(92.2 \%)$ & \\
\hline \multirow[t]{2}{*}{ Adherent to diet plan } & Yes & $17(18.5 \%)$ & $75(81.5 \%)$ & $0.004^{*}$ \\
\hline & No & $0(0.0 \%)$ & $40(100.0 \%)$ & \\
\hline \multirow[t]{2}{*}{ Adherent to treatment plan } & Yes & $16(15.2 \%)$ & $89(84.8 \%)$ & $0.194^{* * *}$ \\
\hline & No & $1(3.7 \%)$ & $26(96.3 \%)$ & \\
\hline \multirow[t]{2}{*}{ Physically active } & Yes & $11(16.4 \%)$ & $56(83.6 \%)$ & $0.231^{*}$ \\
\hline & No & $6(9.4 \%)$ & $58(90.6 \%)$ & \\
\hline \multirow{3}{*}{$\begin{array}{l}\text { Social and family support } \\
\text { [mean } \pm \text { SD] }\end{array}$} & Score on support needed scale & $4.2 \pm 0.66$ & $3.8 \pm 0.9$ & $0.160^{* *}$ \\
\hline & Score on support received scale & $3.7 \pm 0.9$ & $3.2 \pm 1.0$ & $0.056^{* *}$ \\
\hline & Score on support attitude scale & $4.1 \pm 0.9$ & $3.7 \pm 0.9$ & $0.067^{* *}$ \\
\hline \multirow{2}{*}{$\begin{array}{l}\text { Support received from family and } \\
\text { friends }\end{array}$} & Yes & $4(6.6 \%)$ & 57 (93.4 \%) & $0.032^{*}$ \\
\hline & No & $13(19.4 \%)$ & $54(80.6 \%)$ & \\
\hline
\end{tabular}

* Chi square test; ${ }^{* *}$ Independent sample $t$ test; ${ }^{* * *}$ Fisher's exact test 
We observed a significant positive correlation between support attitude and support received from family and friends. Also, mean score on support received was higher in patients with adequate blood glucose control than that of inadequate control group ( $\mathrm{p}=0.056)$. Receiving support from friends and family was significantly associated with good control of blood glucose level. A mixed-method study previously found that lack of support from friends and family members led to poor management of diabetes which was mediated by less adherence to treatment [36]. We found, as expected, that most of the patients got highest help for their diabetes self-care management from their spouse or family members (58 \%). Therefore, future interventions for diabetes control and prevention should also involve family members and/or primary caregivers in order to improve their motivation and behavioral skills to offer greater support to the diabetes patients.

Only $71 \%$ of the surveyed type 2 diabetes patients had overall good perception about their diabetes management. This finding is very alarming because most of these patients actually had poor blood glucose control. Therefore, patient education about good glycemic management is very crucial in order to achieve and maintain better control over diabetes status to stall further complications. We found association between global satisfaction with current diabetic care and adequate blood glucose control among T2DM patients, similar to another study published previously [29].

To the best of our knowledge, this study is the first study in Bangladesh that draws attention to attitude towards diabetes and social and family support among type 2 diabetes patients. However, we were not able to provide any causal inferences between them from this cross-sectional study. Therefore, prospective study involving large number of T2DM patients is warranted to assess the relationship between attitude towards diabetes and support from friends and family and prognosis of diabetes.

There are several limitations of this study. Convenience sampling of the type 2 diabetes patients attending a tertiary hospital, who might be systematically different from the general population, hence might introduce selection bias in the estimates. However, the prevalence of inadequate blood glucose control among T2DM patients not seeking healthcare might be even higher than that of our study sample. Additionally, the study had smaller sample size and information about diabetes were self-reported. However, these findings add to the body of knowledge of diabetes control and prevention of diabetes-related complications among T2DM patients.

\section{Conclusions}

In conclusion, our study found very high proportions of inadequate blood glucose control among T2DM patients. This might contribute to increased incidence of various macro-vascular and micro-vascular diabetic complications and incur huge economic burden on the healthcare system. Positive attitude towards diabetes management and support from friends and family were associated with adequate diabetes management. Such knowledge will aid the health professionals and policy makers to develop and ensure good quality diabetic care and health education. Moreover, appropriate public health interventions should be designed to educate and motivate the family members to offer greater support to the diabetes patients.

\section{Abbreviations \\ DCP: diabetes care profile; DMCH: Dhaka Medical College Hospital; HbA1c: glycated hemoglobin; IDF: International Diabetes Federation; LMICs: Iow and middle income countries; OAA: oral anti-hyperglycemic agents; SACMO: sub-assistant community medical officer; SD: standard deviation; T2DM: type 2 diabetes mellitus.}

\section{Authors' contributions}

MSRS and FBH initiated the study and took part in study design, implementation, data analysis and manuscript writing. RDG, MRH and MFR were responsible for study implementation and data entry. GA analyzed the data and reviewed the draft manuscript. GUA provided overall guidance in designing and implementation of the study and reviewed the manuscript. All authors critically reviewed manuscript. All authors read and approved the final manuscript.

\section{Author details}

1 Department of Public Health, North South University, Bashundhara, Dhaka 1229, Bangladesh. ${ }^{2}$ Dhaka Medical College, Secretariate Rd, Dhaka 1000, Bangladesh.

\section{Acknowledgements}

We would like to acknowledge the support of the participating patients, unit heads and doctors of all medicine units in Dhaka medical college hospital and authority of DMCH for their unconditional support in this research. We would like to extend our gratitude towards Dr. Md. Akhter Hossain, Dr. Ariful Bari Chowdhury and Dr. Mohammad Hyatun Nabi for their guidance and feedback in data analysis and manuscript preparation.

\section{Availability of data and materials}

The dataset supporting the conclusions of this article is not included within the article due to protection patient confidentiality.

\section{Competing interests}

The authors declare that they have no competing interests.

\section{Ethical consideration}

Informed verbal consent was taken from each participants after understanding the aims and objectives of the research and associated risk and benefits of participating in the study. Privacy, anonymity and confidentiality were maintained at all stages of data collection and analysis. Ethical approval was taken from institutional review committee of Dhaka medical college hospital, Dhaka, Bangladesh.

Received: 20 August 2015 Accepted: 9 May 2016

Published online: 26 May 2016

\section{References}

1. Wild S, Roglic G, Green A, Sicree R, King H. Global prevalence of diabetes: estimates for the year 2000 and projections for 2030. Diabetes Care. 2004;27:1047-53. 
2. Whiting DR, Guariguata L, Weil C, Shaw J. IDF diabetes atlas: global estimates of the prevalence of diabetes for 2011 and 2030. Diabetes Res Clin Pract. 2011:94:311-21.

3. Guariguata L, Whiting DR, Hambleton I, Beagley J, Linnenkamp U, Shaw JE. Global estimates of diabetes prevalence for 2013 and projections for 2035. Diabetes Res Clin Pract. 2014;103:137-49.

4. Hussain A, Rahim MA, Azad Khan AK, Ali SMK, Vaaler S. Type 2 diabetes in rural and urban population: diverse prevalence and associated risk factors in Bangladesh. Diabet Med. 2005;22:931-6.

5. Hussain A, Claussen B, Ramachandran A, Williams R. Prevention of type 2 diabetes: a review. Diabetes Res Clin Pract. 2007:76:317-26.

6. International Diabetes Federation. IDF diabetes atlas sixth edition. idf.org. 2014;1-2.

7. Saquib N, Saquib J, Ahmed T, Khanam MA, Cullen MR. Cardiovascular diseases and type 2 diabetes in Bangladesh: a systematic review and meta-analysis of studies between 1995 and 2010. BMC Public Health. 2012;12:434.

8. Saquib N, Khanam MA, Saquib J, Anand S, Chertow GM, Barry M, et al. High prevalence of type 2 diabetes among the urban middle class in Bangladesh. BMC Public Health. 2013;13:1032.

9. Misra R, Lager J. Ethnic and gender differences in psychosocial factors, glycemic control, and quality of life among adult type 2 diabetic patients. J Diabetes Complicat. 2009;23:54-64.

10. Bonds DE, Camacho F, Bell RA, Duren-Winfield VT, Anderson RT, Goff DC. The association of patient trust and self-care among patients with diabetes mellitus. BMC Fam Pract. 2004;5:26.

11. Reichard $\mathrm{P}$, Nilsson BY, Rosenqvist $\mathrm{U}$. The effect of long-term intensified insulin treatment on the development of microvascular complications of diabetes mellitus. N Engl J Med. 1993;329:304-9.

12. UK Prospective Diabetes Study. UKPDS) Group. Intensive blood-glucose control with sulphonylureas or insulin compared with conventional treatment and risk of complications in patients with type 2 diabetes (UKPDS 33. Lancet. 1998:352:837-53.

13. Khattab M, Khader YS, Al-Khawaldeh A, Ajlouni K. Factors associated with poor glycemic control among patients with type 2 diabetes. J Diabetes Complicat. 2010;24:84-9.

14. Karter AJ, Moffet HH, Liu J, Parker MM, Ahmed AT, Ferrara A, et al. Achieving good glycemic control: initiation of new antihyperglycemic therapies in patients with type 2 diabetes from the Kaiser Permanente Northern California Diabetes Registry. Am J Manag Care. 2005;11:262-70.

15. Kneckt MC, Keinanen-Kiukaanniemi SM, Knuuttila ML, Syrjala AM. Selfesteem as a characteristic of adherence to diabetes and dental self-care regimens. J Clin Periodontol. 2001;28:175-80.

16. Lloyd CE, Dyer PH, Lancashire RJ, Harris T, Daniels JE, Barnett AH. Association between stress and glycemic control in adults with type 1 (insulindependent) diabetes. Diabetes Care. 1999:22:1278-83.

17. Aalto AM, Uutela A, Aro AR. Health related quality of life among insulindependent diabetics: disease-related and psychosocial correlates. Patient Educ Couns. 1997:30:215-25.

18. Gentili P, Maldonato A, Grieco R, Santini A. Influence of patients' representations and beliefs about diabetes and its treatment on their adherence to therapy. Diabetes Nutr Metab. 2001;14:140-52.

19. Karlsen B, Bru E. Coping styles among adults with type 1 and type 2 diabetes. Psychol Health Med. 2002;7:245-59.
20. McDonald PE, Wykle ML, Misra R, Suwonnaroop N, Burant CJ. Predictors of social support, acceptance, health-promoting behaviors, and glycemic control in African-Americans with type 2 diabetes. J Natl Black Nurses Assoc. 2002;13:23-30.

21. Williams KE, Bond MJ. The roles of self-efficacy, outcome expectancies and social support in the self-care behaviours of diabetics. Psychol Health Med. 2002;7:127-41.

22. Toljamo M, Hentinen M. Adherence to self-care and social support. J Clin Nurs. 2001;10:618-27.

23. Tillotson LM, Smith MS. Locus of control, social support, and adherence to the diabetes regimen. Diabetes Educ. 1996:22:133-9.

24. Rubin RR, Peyrot M. Quality of life and diabetes. Diabetes Metab Res Rev. 1999:15:205-18.

25. Nouwen A, Gingras J, Talbot F, Bouchard S. The development of an empirical psychosocial taxonomy for patients with diabetes. Health Psychol. 1997;16:263-71.

26. Dhaka Medical College. 2016. http://www.dmc.edu.bd/. Accessed 18 Apr 2016.

27. Fitzgerald JT, Davis WK, Connell CM, Hess GE, Funnell MM, Hiss RG. Development and validation of the diabetes care profile. Eval Health Prof. 1996;19:208-30.

28. Michigan Diabetes Research Center (MDRC). 2016. http://www.diabetesresearch.med.umich.edu/. Accessed 18 Apr 2016.

29. Moreira EDJ, Neves RCS, Nunes ZO, de Almeida MCC, Mendes ABV, Fittipaldi JAS, et al. Glycemic control and its correlates in patients with diabetes in Venezuela: results from a nationwide survey. Diabetes Res Clin Pract. 2010:87:407-14.

30. Fox KM, Gerber Pharmd RA, Bolinder B, Chen J, Kumar S. Prevalence of inadequate glycemic control among patients with type 2 diabetes in the United Kingdom general practice research database: A series of retrospective analyses of data from 1998 through 2002. Clin Ther. 2006;28:388-95.

31. Shah BR, Hux JE, Laupacis A, Mdcm BZ, Austin PC, van Walraven C. Diabetic patients with prior specialist care have better glycaemic control than those with prior primary care. J Eval Clin Pract. 2005;11:568-75.

32. Mendes ABV, Fittipaldi JAS, Neves RCS, Chacra AR, Moreira EDJ. Prevalence and correlates of inadequate glycaemic control: results from a nationwide survey in 6671 adults with diabetes in Brazil. Acta Diabetol. 2010;47:137-45.

33. Harris SB, Ekoe JM, Zdanowicz Y, Webster-Bogaert S. Glycemic control and morbidity in the Canadian primary care setting (results of the diabetes in Canada evaluation study). Diabetes Res Clin Pract. 2005;70:90-7.

34. Goudswaard AN, Stolk RP, Zuithoff P, Rutten GEHM. Patient characteristics do not predict poor glycaemic control in type 2 diabetes patients treated in primary care. Eur J Epidemiol. 2004;19:541-5.

35. Hoerger TJ, Segel JE, Gregg EW, Saaddine JB. Is glycemic control improving in U.S. adults? Diabetes Care. 2008;31:81-6.

36. Mayberry LS, Osborn CY. Family support, medication adherence, and glycemic control among adults with type 2 diabetes. Diabetes Care. 2012;35:1239-45.

\section{Submit your next manuscript to BioMed Central and we will help you at every step:}

- We accept pre-submission inquiries

- Our selector tool helps you to find the most relevant journal

- We provide round the clock customer support

- Convenient online submission

- Thorough peer review

- Inclusion in PubMed and all major indexing services

- Maximum visibility for your research

Submit your manuscript at www.biomedcentral com/submit
BioMed Central 